Plant Tissue Cult. \& Biotech. 18(2): 89-102, 2008 (December)

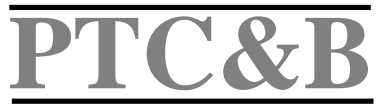

\title{
Purification and Partial Characterization of Lectins from In vitro Cultures of Ricinus communis
}

\author{
Harshita Chaudhary and Neelu Sood*
}

Department of Biotechnology, Guru Nanak Dev University, Amritsar-143 005, India

Key words: Ricinus communis, Lectins, In vitro, Micropropagation, Ricin, RCA, Haemagglutination, Purification and Characterization

\begin{abstract}
Ricinus lectins have proven to be quite useful in biological and medical research because of their haemagglutinating, mitogenic, antitumor and toxic properties. In the Indian medicine system, the leaf, root and seed oil of this plant species have been used for the treatment of inflammation and liver disorders. The two major lectins Ricin and RCA have toxic and haemagglutination activities. The micropopagation of Ricinus was standardized using MS medium supplemented with different concentrations of IAA, IBA, NAA, BAP and Kinetin. Kinetin (0.5 $\mathrm{mg} / \mathrm{l})+\mathrm{NAA}(1.0 \mathrm{mg} / \mathrm{l})$ combination was found to be optimal for raising in vitro complete plants within 4 weeks. Using Affinity chromatography galactose binding lectins were isolated from the in vitro grown plants, in vivo leaves and mature seeds. The isolated fractions were further characterized for their molecular weight using SDS-PAGE, haemagglutination activity, $\mathrm{pH}$ and thermostability. In the purified fractions, the protein bands other than those corresponding to reported subunits of Ricinus lectins, indicated the presence of some more hitherto unexplored lectins. However, the seeds proved to be a rich source of lectins more than in in vitro grown plants. The seeds are available only from the mature plant at the end of growing season, hence consistent supply of lectins is not possible using conventional methods. Thus in vitro raised plants can prove to be rich source of lectins other than seeds, which can be of great therapeutic and commercial use.
\end{abstract}

\section{Introduction}

Lectins are carbohydrate-binding proteins that are widely distributed in the plant and animal kingdom. Lectins are being explored as rich source of biomedicine due to their haemagglutinating, mitogenic and toxic properties. It is believed that most plant lectins are directed against foreign glycans and they can interact with other organisms as well. Mode of interaction is recognition or defence based (Van Damme et al. 1998, Peumans 2000). The recent finding suggests that malignant cells are often more easily agglutinated by lectins than

*Present address: Department of Botany, Kurukshetra University, Kurukshetra 136119, India. E-mail corresponding author: <neelusood61@yahoo.com>. 
the related normal cells. This selective agglutination might be used in cancer therapy which has stimulated work on the structure and properties of lectins. Their characteristics have also been extensively exploited in many aspects of biochemistry and biomedicine (Pusztai 1993). The main properties of lectins are based on their ability to interact with carbohydrates and thus combine with glyco components on the cell surface, leading to their distinct biological role (Goldstein and Poretz 1986). Lectins vary in molecular size, amino acid composition, metal ion requirements, and three-dimensional structure (Sharon 1993).

Plant lectins can be broadly classified in seven families of proteins, indicating that plants developed only a limited number of carbohydrate-binding motifs. Although numerous plant lectins have been studied in great detail, yet physiological role of these proteins is still poorly understood.

Castor plant (Ricinus communis L.) is an oilseed plant. Castor oil has unique physical and chemical properties among the vegetative oils and has found wide applications in modern technology. The seeds of the castor bean have been recognized for their toxicity since time immemorial. Due to industrialization and population increase this plant is chopped off from its wild habitat. Also, it is reported to suffer severe losses due to many diseases caused by fungi and bacteria. Seeds are the main source of lectins and castor seeds suffer from a disease called 'Seedling Blight'. Castor plants are normally monoceious, with male flowers on the upper portion of the raceme and female on the lower. Flowers of both types can also be interspersed along the length of the raceme. The proportion of male and female flowers on each raceme varies and can be influenced by the environment (Weiss 1983). It bears seeds annually, thus the seeds are available only during termination of growing season hence consistent supply of lectin from Ricinus is not possible using conventional methods.

\section{Materials and Methods}

Ricinus communis leaves, shoot tips and seeds were obtained from the surroundings of the Guru Nanak Dev University, Amritsar, India. The required quantities of stock solutions for preparation of MS medium were poured in beaker supplemented with sucrose $3 \%$ and myo-inositol $100 \mathrm{mg} / \mathrm{l} . \mathrm{pH}$ was adjusted to 5.7 using $1 \mathrm{~N} \mathrm{NaOH}$ and final volume of medium was scaled up to 1 litre with Milli $\mathrm{Q}$ water. The prepared MS medium was warmed in microwave oven and supplemented with $0.8 \%$ agar. Different growth regulators (BAP, Kn, IAA, IBA, NAA singly and in combination) were supplemented with 0.5, 1.0, 1.5, 2.0, $2.5 \mathrm{mg} / \mathrm{l}$. Medium was poured in test tubes, finally autoclaved at $15 \mathrm{lbs} / \mathrm{sq}$ inch at $121^{\circ} \mathrm{C}$ for $20 \mathrm{~min}$ and allowed to cool at room temperature. 
Explants were cut into appropriate size and washed in tap water thoroughly followed by rinse with dilute savlon solution and finally with distilled water three times. Explants were transferred into a sterile flask, which contained $0.1 \%$ mercuric chloride solution for $5 \mathrm{~min}$ for surface sterilization under sterilized laminar flow hood.

The inoculations were carried out in horizontal laminar flow hood that was thoroughly swabbed with alcohol and surface sterilized with UV light for $30 \mathrm{~min}$ prior to inoculation. The sterilized explants were inoculated on MS medium with different growth regulators. The inoculated culture tubes were transferred in culture room with controlled light and temperature at $25 \pm 2^{\circ} \mathrm{C}$ and $1200 \mathrm{lux} / \mathrm{M}^{2}$ light.

The fresh weight of seeds, leaves from in vivo plants, in vitro raised plants and callus of Ricinus communis was recorded. The seeds were ground to a fine powder and defatted using chilled acetone $(1: 5 \mathrm{w} / \mathrm{v}$ ). The leaves (in vitro and in vivo) were crushed in liquid nitrogen. The defatted and dried seed powder, callus, crushed leaves were homogenized separately in a blender with $0.01 \mathrm{M}$ phosphate buffered saline $(1: 5 \mathrm{w} / \mathrm{v})$ at $\mathrm{pH}$ 7.2. The homogenate was filtered using several layers of cheese cloth and centrifuged at 10,000 rpm for 30 minutes at $4^{\circ} \mathrm{C}$. The supernatant obtained was extensively dialyzed against $0.01 \mathrm{M}$ phosphate buffered saline (PBS) overnight under cold condition and stored at $20^{\circ} \mathrm{C}$ for further use. The final supernatants contained crude lectins.

The protein concentration of all samples (seeds, leaves from in vivo plants, in vitro raised plants and callus) was determined by Bradford's method (Bradford, 1976) using bovine serum albumin (BSA) as the standard.

Chromatographic columns with asialofetuin linked amino activated silica beads matrix were procured from Molecular Biology and Biochemistry Department of Guru Nanak Dev university, Amritsar. The column was washed with $0.01 \mathrm{M}$ PBS. Crude sample (from seed, leaves of in vivo and in vitro raised plants) was loaded (15 - $20 \mu \mathrm{g}$ protein) in the column and recirculated two - three times. The column was washed with $200-300 \mathrm{ml}$ of PBS. The galctose binding proteins were eluted by giving a $\mathrm{pH}$ shock with $0.1 \mathrm{M}$ glycine- $\mathrm{HCl}$ buffer $(\mathrm{pH}$ 2.5). The elutions were neutralized using $2 \mathrm{M}$ Tris- $\mathrm{HCl}$ buffer ( $\mathrm{pH} 9.0$ ). Three $\mathrm{ml}$ elutions were used for reading absorbance at $280 \mathrm{~nm}$. Different elutions were elutions were used for reading absorbance at $280 \mathrm{~nm}$. Different elutions were

Agglutination of the red blood cells by the crude extract and various fractions that were obtained during purification were estimated as described before by Bing et al. (1967). In a U-shaped microtitre plate arranged in rows of wells, 1: 1 dilutions of the sample in PBS buffer were mixed with erythrocyte suspension $\left(3.5 \times 10^{8} / \mathrm{ml}\right)$. The plate was left undisturbed for $30 \mathrm{~min}$ to $1 \mathrm{hr}$ at room temperature to allow agglutination. The titre value of the lectin was 
expressed as the reciprocal of the highest dilution showing visible agglutination of erythrocytes.

The blood group specificity of the extract was established using erythrocytes from different blood groups of the ABO system.

The sugar specificity of the lectin was investigated by the ability of galactose to inhibit the agglutination of human erythrocytes. Twofold dilutions of sugar (1 M initial concentration) solutions in PBS were mixed with the lectin solution $(10 \mu \mathrm{g})$ of different samples and allowed to react for 30 minutes at room temperature. An erythrocyte suspension $(30 \mu \mathrm{l})$ was then added and the mixture was left for another $30 \mathrm{~min}$. The haemagglutinating titers thus were obtained were compared with a non-sugar containing blank. The titer value of the inhibition assay was expressed as the reciprocal of the highest dilution inhibiting agglutination of erythrocytes.

The effect of temperature on the haemagglutinating activity was monitored, as described by Sampaio et al. (1998). Aliquots of lectin were incubated at different temperatures $\left(4,30,60\right.$ and $\left.90^{\circ} \mathrm{C}\right)$. The heated solution was rapidly cooled in ice and assayed for agglutinating activity. Agglutinating activity of the control that was kept at $-20^{\circ} \mathrm{C}$ for 30 min was used as a reference.

The effect of $\mathrm{pH}$ on the haemagglutinating activity was determined by carrying out the haemagglutinating assay of the lectin using the following buffers at different $\mathrm{pH}$ values; $0.1 \mathrm{M}$ glycine-NaOH buffer, $\mathrm{pH}$ (9 and 11), $0.1 \mathrm{M}$ glycine $\mathrm{HCl}$ buffer, $\mathrm{pH}$ (3 and 5), and 0.01 M PBS buffer, pH 7.0. Haemagglutination in case of $\mathrm{pH} 7.0$ was taken as reference control.

SDS-PAGE $(10 \%)$ was carried out in Bio Rad apparatus in a tris-glycine buffer, $\mathrm{pH} 8.9$ (according to the Bio Rad manual). The proteins were stained using silver staining, while the presence of covalently bound sugar in the lectin was detected by staining the gels with chromic acid Schiff's reagent specific for glycoproteins.

The gel was dipped overnight in 50\% methanol and the washed thrice with Milli Q water. It was the dipped in 50\% ethanol for $30 \mathrm{~min}$ and washed thrice. $0.2 \%$ sodium thiosulfate solution was used to submerge the gel for $20 \mathrm{sec}$ followed by thorough washings. $0.2 \%$ silver nitrate solution was applied for 30 min. $6 \%$ sodium carbonate was used to visualize the bands and the gel was washed with $1 \%$ glacial acetic acid, which acts as stopper. $50 \%$ methanol was used for storage of gels.

The gel was dipped in methanol (50\%) for $1 \mathrm{hr}$. The proteins were oxidized with $1 \%$ chromic acid in $3 \%$ acetic acid solution for $1 \mathrm{~h}$. After washing with DDW thrice, $200 \mathrm{ml}$ of Schiff's reagent was added and kept on shaker for $2 \mathrm{hr}$. Excess of stain was removed with 3 washings with sodium metabisulphite $(50 \mathrm{~g} / \mathrm{l})$ in dilute glacial acetic acid $(50 \mathrm{ml} / \mathrm{l})$. 
The gels were captured using Alphaease ${ }^{\mathrm{TM}}$ and analysed for molecular weight studies using Alphaease software.

The data analysis was done using Sigmastat 3.5. To analyze the significance of difference t-test was made. Values of $p>0.05$ were considered significant.

\section{Results and Discussion}

MS medium was supplemented with different concentrations of $\mathrm{Kn}$ and BAP and IAA, IBA and NAA. In case of Kn and BAP showed optimal growth at $0.5 \mathrm{mg} / 1$ supplementation, as there was significant increase in the number of leaves and shoots as compared to plants grown on basal and other media but no visible root growth occurred (Fig. 1). In case of $1.0 \mathrm{mg} / \mathrm{l}$ each of IAA, IBA or NAA had best growth promoting effects with increased number of roots but poor shoots and small leaves. Higher concentrations were able to promote the root growth weakly. The combination of kinetin with different concentrations of auxins showed that $0.5 \mathrm{mg} / 1 \mathrm{Kn}$ and $1.0 \mathrm{mg} / 1$ each of IAA, IBA or NAA yielded overall optimum response with respect to shoot and root growth (Table 1). The $0.5 \mathrm{mg} / 1$ $\mathrm{Kn}+1.0 \mathrm{mg} / 1 \mathrm{NAA}$ showed best effects to give whole in vitro raised plants with palm shaped healthy leaves, elongated shoots and thick roots. The callus formation occurred only on MS medium supplemented with 0.5 - $2.0 \mathrm{mg} / 1$ 2, 4-D out of all the media tried with different concentrations.

The crude lectins obtained from all the samples (four weeks old in vitro raised plants, immature leaves of in vivo plants and seeds) were analysed for SDS-PAGE and their haemagglutination assay (Fig. 4).

SDS-PAGE of the crude extract proteins isolated from the dry castor bean seeds, in vivo plant leaves, callus and in vitro raised plants was carried out (Fig. 2). Differences in the protein profiles were observed. There was clearly variable expression of different proteins in the seeds, callus, leaves and in vitro raised plants. The protein bands corresponding to $24.72 \mathrm{kDa}$ in case of seed were absent in all the other three samples. 53.28, 37.76, 35.34 and $31.93 \mathrm{kDa}$ proteins were highly prominent in seed samples where as 28.22 and $26.88 \mathrm{kDa}$ proteins were more expressed in case of all the samples except seeds.

Equal amount of proteins from different samples showed different titre values. The seeds showed highest titre value and agglutination activity followed by callus, in vitro raised plants and in vivo plant leaves (Table 2).

The isolation and purification of the lectin from the dry castor bean seeds, in vivo plant leaves, and in vitro raised plants. The four elutions identified were used for SDS-PAGE, Haeamagglutination assay, D-Galactose inhibition assay and effect of $\mathrm{pH}$ as well was temperature on the purified lectins. 
Table 1(a). Morphogenetic data of four-week-old shoot tip culture of Ricinus communis grown on MS basal medium.

\begin{tabular}{cccc}
\hline Media & No. of leaves & No. of shoots & No. of roots \\
\hline MS medium & $2.81 \pm 0.19$ & $2.81 \pm 0.19$ & 0 \\
\hline
\end{tabular}

Table 1(b). Morphogenetic data of four-week-old shoot tip culture of Ricinus communis grown on MS supplemented with BAP or Kn.

\begin{tabular}{ccccccc}
\hline \multirow{2}{*}{$\begin{array}{c}\text { BAP/Kn } \\
(\mathrm{mg} / \mathrm{l})\end{array}$} & \multicolumn{2}{c}{ No. of leaves } & \multicolumn{2}{c}{ No. of shoots } & \multicolumn{2}{c}{ No. of roots } \\
\cline { 2 - 7 } & BAP & Kn & BAP & Kn & BAP & Kn \\
\hline 0.5 & $8.76 \pm 0.23$ & $6.79 \pm 0.21$ & $10.75 \pm 0.25$ & $7.80 \pm 0.20$ & 0 & 0 \\
1.0 & $5.76 \pm 0.23$ & $4.77 \pm 0.23$ & $6.96 \pm 0.04$ & $5.69 \pm 0.31$ & 0 & 0 \\
1.5 & $3.76 \pm 0.23$ & $3.71 \pm 0.29$ & $4.86 \pm 0.14$ & $4.77 \pm 0.23$ & 0 & 0 \\
2.0 & $2.86 \pm 0.14$ & $2.81 \pm 0.19$ & $3.86 \pm 0.14$ & $3.71 \pm 0.29$ & 0 & 0 \\
2.5 & $1.96 \pm 0.04$ & $1.69 \pm 0.31$ & $2.69 \pm 0.31$ & $2.81 \pm 0.19$ & 0 & 0 \\
\hline
\end{tabular}

Table 1(c). Morphogenetic data of four-week-old shoot tip culture of Ricinus communis grown on MS supplemented with IAA, IBA or NAA.

\begin{tabular}{cccccccccc}
\hline $\begin{array}{c}\text { IAA/IBA } \\
\text { /NAA } \\
(\mathrm{mg} / \mathrm{l})\end{array}$ & \multicolumn{3}{c}{ No. of leaves } & \multicolumn{3}{c}{ No. of shoots } & \multicolumn{3}{c}{ No. of roots } \\
\cline { 2 - 10 } & & IBA & NAA & IAA & IBA & NAA & IAA & IBA & NAA \\
\hline 0.5 & $2.81 \pm$ & $1.69 \pm$ & $1.00 \pm$ & $3.71 \pm$ & $2.81 \pm$ & $1.69 \pm$ & $3.71 \pm$ & $2.81 \pm$ & $5.69 \pm$ \\
& 0.19 & 0.31 & 0.33 & 0.29 & 0.19 & 0.31 & 0.29 & 0.19 & 0.31 \\
1.0 & $2.81 \pm$ & $1.69 \pm$ & $1.00 \pm$ & $3.71 \pm$ & $1.69 \pm$ & $1.69 \pm$ & $3.71 \pm$ & $2.81 \pm$ & $7.80 \pm$ \\
& 0.19 & 0.31 & 0.33 & 0.29 & 0.31 & 0.31 & 0.29 & 0.19 & 0.20 \\
1.5 & $1.00 \pm$ & 0 & 0 & $1.69 \pm$ & $1.00 \pm$ & $1.69 \pm$ & $2.81 \pm$ & $1.69 \pm$ & $4.77 \pm$ \\
& 0.33 & & & 0.31 & 0.33 & 0.31 & 0.19 & 0.31 & 0.33 \\
2.0 & 0 & 0 & 0 & $1.00 \pm$ & $1.00 \pm$ & $1.00 \pm$ & $1.69 \pm$ & $1.00 \pm$ & $2.81 \pm$ \\
& & & & 0.33 & 0.33 & 0.33 & 0.31 & 0.33 & 0.19 \\
2.5 & 0 & 0 & 0 & $1.00 \pm$ & $1.00 \pm$ & $1.00 \pm$ & $1.00 \pm$ & $1.00 \pm$ & $1.00 \pm$ \\
& & & & 0.33 & 0.33 & 0.33 & 0.33 & 0.33 & 0.33 \\
\hline
\end{tabular}

Table 1(d). Morphogenetic data of four-week-old shoot tip culture of Ricinus communis grown on MS supplemented with Kn + IAA, IBA or NAA.

\begin{tabular}{cccccccccc}
\hline \multirow{2}{*}{\begin{tabular}{c} 
Kn +IAA/ \\
IBA/NAA \\
\cline { 2 - 10 }$(\mathrm{mg} / \mathrm{l})$
\end{tabular}} & IAA & IBA & NAA & IAA & IBA & NAA & IAA & IBA & NAA \\
\hline $0.5+0.5$ & $2.81 \pm$ & $2.81 \pm$ & $2.81 \pm$ & $3.71 \pm$ & $3.71 \pm$ & $3.71 \pm$ & $2.81 \pm$ & $2.81 \pm$ & $6.79 \pm$ \\
& 0.19 & 0.19 & 0.19 & 0.29 & 0.29 & 0.29 & 0.19 & 0.19 & 0.21 \\
$0.5+1.0$ & $3.71 \pm$ & $2.81 \pm$ & $3.71 \pm$ & $4.77 \pm$ & $3.71 \pm$ & $4.77 \pm$ & $3.71 \pm$ & $2.81 \pm$ & $7.80 \pm$ \\
& 0.29 & 0.19 & 0.29 & 0.23 & 0.29 & 0.23 & 0.29 & 0.19 & 0.20 \\
$0.5+1.5$ & $1.69 \pm$ & $2.81 \pm$ & $1.69 \pm$ & $2.81 \pm$ & $2.81 \pm$ & $2.81 \pm$ & $1.69 \pm$ & $1.69 \pm$ & $3.71 \pm$ \\
& 0.31 & 0.19 & 0.31 & 0.19 & 0.19 & 0.19 & 0.31 & 0.31 & 0.29 \\
$0.5+2.0$ & $1.69 \pm$ & $1.00 \pm$ & $1.00 \pm$ & $2.81 \pm$ & $2.81 \pm$ & $1.69 \pm$ & $1.69 \pm$ & $1.00 \pm$ & $2.81 \pm$ \\
& 0.31 & 0.33 & 0.33 & 0.19 & 0.19 & 0.31 & 0.31 & 0.33 & 0.19 \\
$0.5+2.5$ & $1.69 \pm$ & $1.00 \pm$ & $1.00 \pm$ & $1.69 \pm$ & $1.69 \pm$ & $1.69 \pm$ & $1.00 \pm$ & $1.00 \pm$ & $1.69 \pm$ \\
& 0.31 & 0.33 & 0.33 & 0.31 & 0.31 & 0.31 & 0.33 & 0.33 & 0.31 \\
\hline
\end{tabular}

Data are representative of five - ten different plants grown on same concentration and expressed as mean \pm SEM. 
All the elutions (I-IV) identified from the three different samples (Fig. 3) agglutinate the human red blood cells of the ABO system non-specifically but with different titre value. The purified elutions from seeds have the highest titer value followed by in vitro raised plants and in vivo plant leaves.
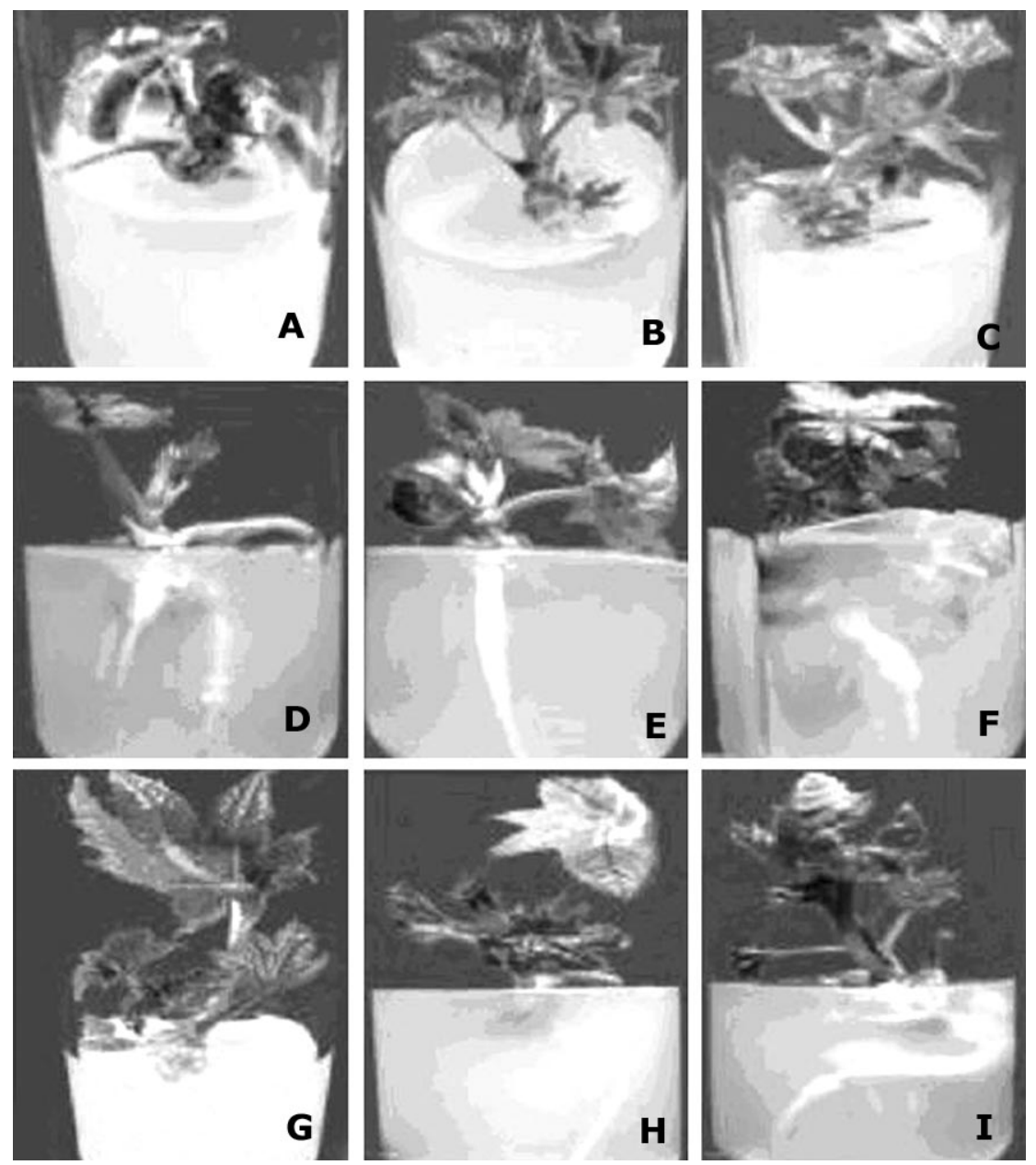

Fig. 1. In vitro raised cultures on MS basal medium and supplemented with different hormones at variable concentrations. Three-week-old shoot tip explant raised on MS (A), MS + 0.5 ppm Kn (B), $\mathrm{MS}+0.5$ ppm BAP (C), MS + 1.0 ppm IAA (D), MS + 1.0 ppm IBA (E), MS + 1.0 ppm NAA (F), MS +0.5 ppm Kn +1.0 ppm IAA $(\mathrm{G}), \mathrm{MS}+0.5 \mathrm{ppm} \mathrm{Kn}+1.0 \mathrm{ppm} \mathrm{IBA}(\mathrm{H}), \mathrm{MS}+0.5 \mathrm{ppm} \mathrm{Kn}+1.0$ ppm NAA (I).

Equal amount of proteins from different samples showed different titre values. The purified elution from seeds showed highest titre value and agglutination activity followed by in vitro raised plants and in vivo plant leaves (Table 2). 
The ability of the different lectins to agglutinate human red blood cells from different blood groups was then tested. It is clear from Table 2 that the Ricinus lectins agglutinate erythrocytes of $\mathrm{ABO}$ blood groups non-specifically and somewhat equally.
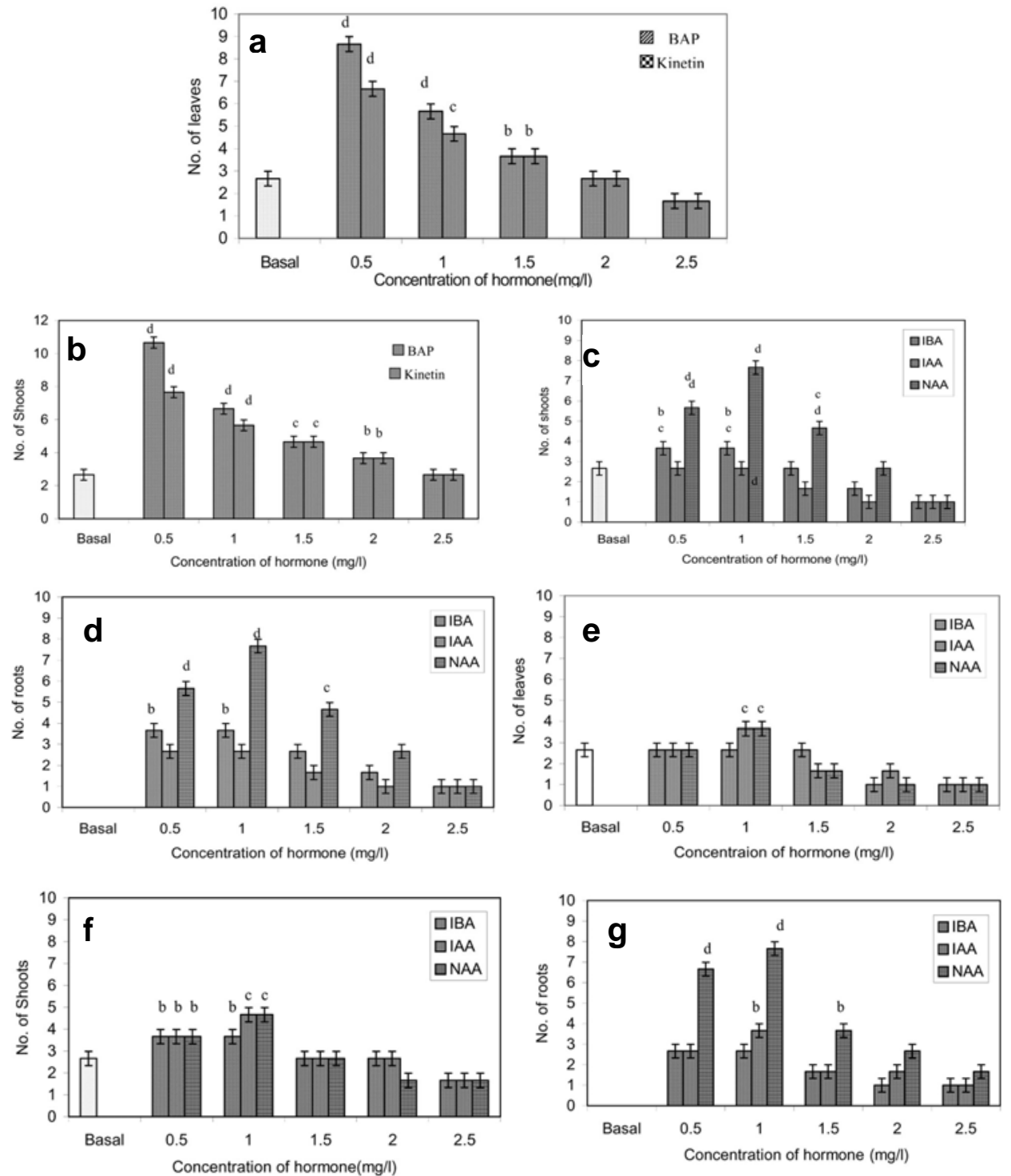

Fig. 2. Morphogentic data graphs showing number of leaves (a) and shoots (b) in in vitro raised fourweek-old plants grown on MS supplemented with Kn and BAP, number of shoots (c) and roots (d) in in vitro raised four-week-old plants grown on MS supplemented with IAA, IBA and NAA growth hormones, number of leaves (e), shoots (f) and roots $(\mathrm{g})$ in in vitro raised four-weeks-old plants grown on MS supplemented with $0.5 \mathrm{ppm} \mathrm{Kn}$ along with IAA, IBA and NAA in different combinations. Data are represented as mean \pm S.E.M of five different plants for each concentration. $\mathrm{b}=\mathrm{p}<0.02, \mathrm{c}=\mathrm{p}<0.01, \mathrm{~d}=\mathrm{p}<0.001$ represent the significant difference as compared with control (basal). 
D-galactose was tested for its inhibitory activity on the purified sample elutions from three sources. Seed elution showed inhibition activity up to titre value of $2^{3}$ while in vitro raised plants elution and in vivo plant leaves elution were found to have titre value of $2^{5}$ and $2^{6}$, respectively.

Table 2. Haemagglutination assay of crude and purified lectins from different samples.

Titer value is expressed as reciprocal of the last dilution showing haemagluttination.

\begin{tabular}{lcc}
\hline Source & $\begin{array}{c}\text { Titer value of crude } \\
\text { extract }\end{array}$ & $\begin{array}{c}\text { Titer value of } \\
\text { purified extract }\end{array}$ \\
\hline Seed & $2^{11}$ & $2^{9}$ \\
Field raised plant leaves & $2^{4}$ & $2^{1}$ \\
In vitro raised plants & $2^{5}$ & $2^{2}$ \\
Callus & $2^{7}$ & - \\
\hline
\end{tabular}

The lectins were remarkably stable in the $\mathrm{pH}$ range of 3.0 - 7.0. The activity, however, falls off fairly rapidly thereafter, with essentially weak activity after $\mathrm{pH}$ 9.0. The lectins showed their normal haeamagglutination activity up to $60^{\circ} \mathrm{C}$ but the activity appeared fairly weak at $90^{\circ} \mathrm{C}$.
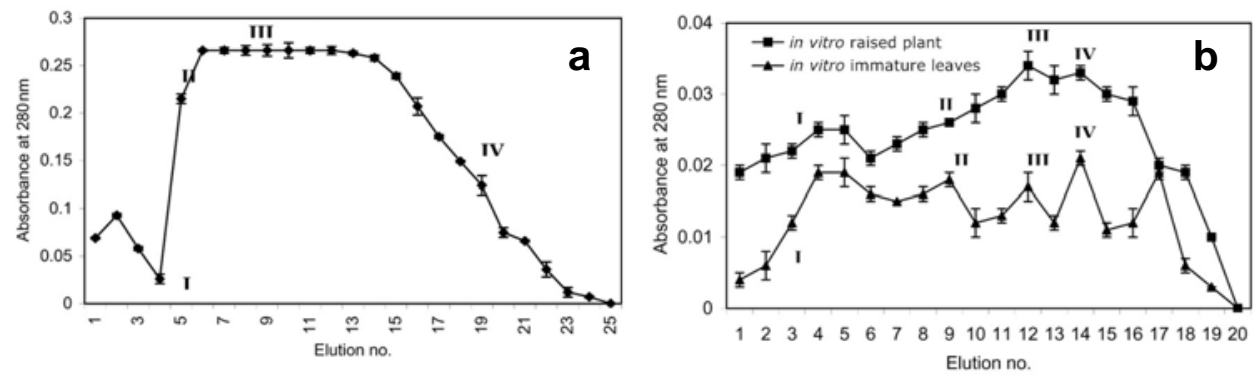

Fig. 3. Absorbance of affinity column chromatography elutions of seed (a), in vitro and in vivo raised plants (b) galactose binding proteins at $280 \mathrm{~nm}$. Data are representative of two different experiments. Each elution was of $3 \mathrm{ml}$. Elutions I, II, III and IV were used to carry out further analysis.

Elutions I - IV from each of the dry castor bean seeds, in vivo plant leaves, and in vitro raised plants purified after affinity chromatography were analysed using SDS-PAGE (Fig. 6). There was multiple bands of varying molecular weight in elution II of seed and elution I of in vitro raised plants but there was no such profile in any of the four elutions in case of in vivo leaves sample. There are low molecular weight galactoses binding proteins present in case of seed elutions but not in other two samples. Also the 31 - $37 \mathrm{kDa}$ proteins are highly expressed in case of seed but lowest in case of in vivo leaves eluted samples. The Schiff's reagent staining confirmed the purified proteins in the elutions as glycoproteins as this stain specifically stains glycoproteins (Fig. 7). 


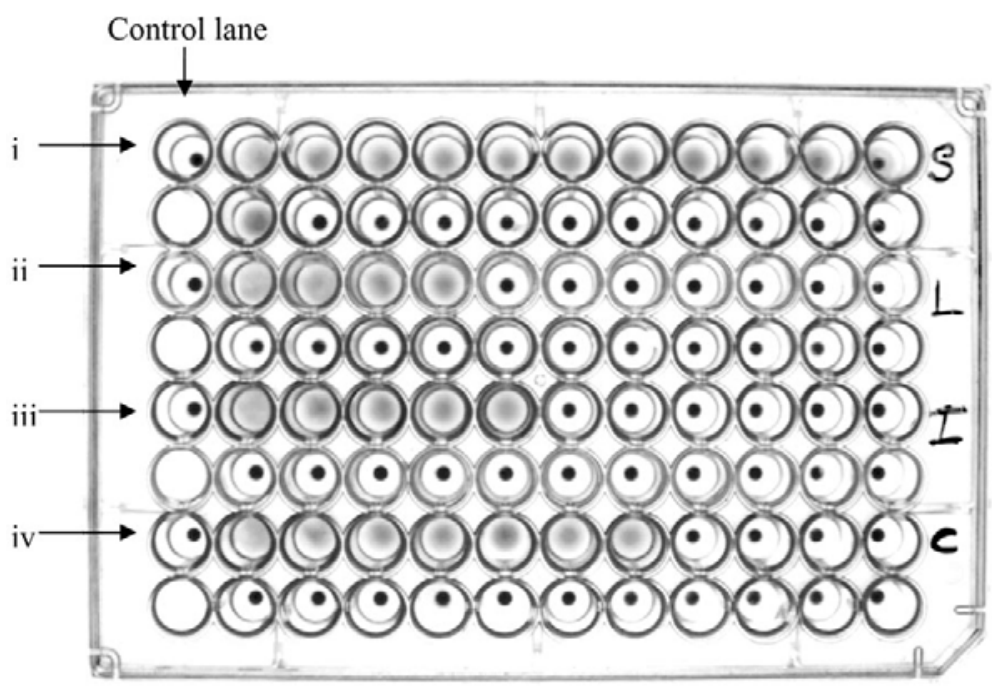

Fig. 4. Hemagglutination assay of the crude lectin extract from seeds (i), in vivo plant leaves (ii), in vitro raised plant leaves (iii) and callus (iv). Ten $\mu \mathrm{g}$ of protein in each sample was diluted serially and kept for $1 \mathrm{hr}$. The last dilution at which the hemagglutinatination appered was assigned as titre value of the sample. The control wells were without crude lectin extract.

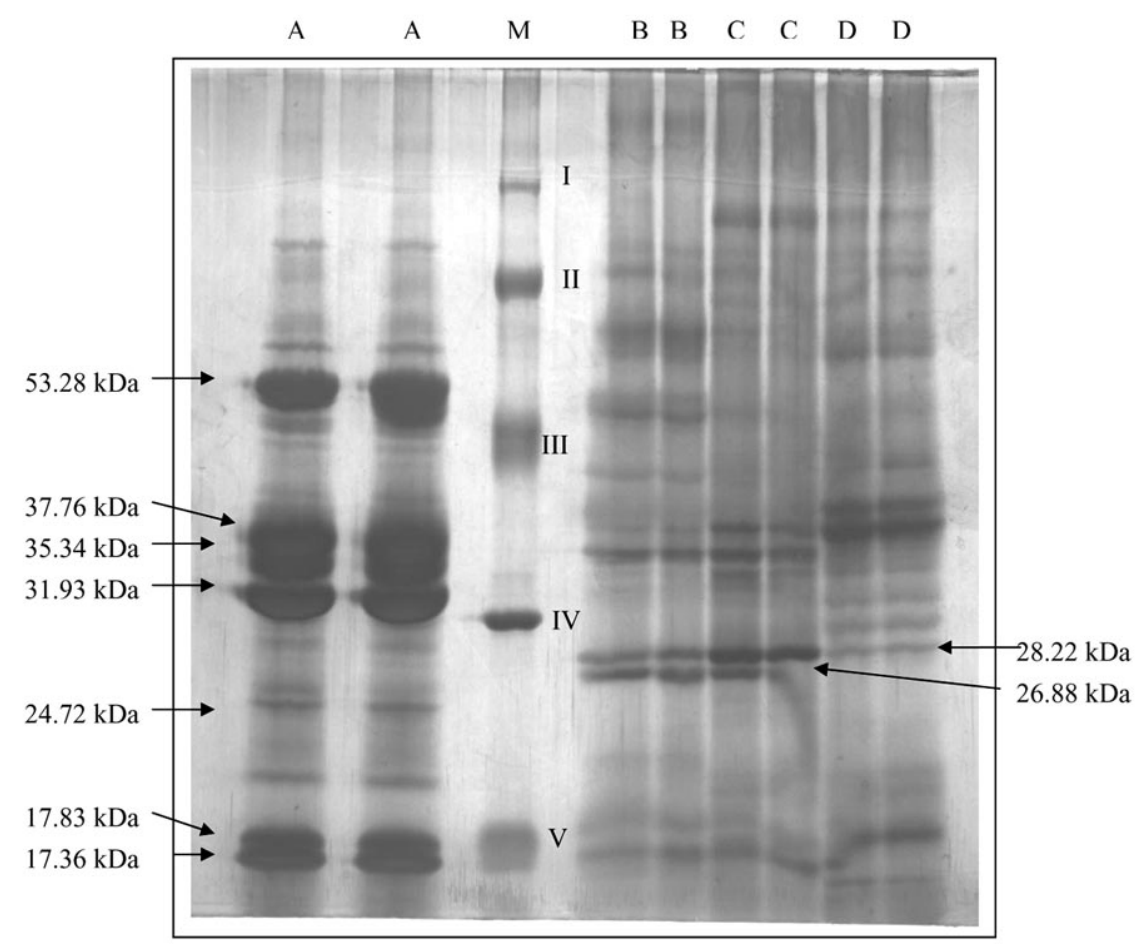


Fig. 5. SDSPAGE of crude extract of seed (A), callus (B), in vitro raised plant leaves (C) and in vivo plant leaves (D). Marker is shown in (M) lane. Molecular marker has molecular weight as I = 97.4, $\mathrm{II}=66.0, \mathrm{III}=43.0, \mathrm{IV}=29.0, \mathrm{~V}=20.1 \mathrm{kDa}$.

The auxin and cytokinin supplementation of the MS basal medium and synergistic combination of these two led to the standardization of in vitro culture conditions for Ricinus communis. The effects of these hormones were clear. The cytokinins (BAP, $\mathrm{Kn}$ ) being the more effective at $0.5 \mathrm{mg} / 1$ concentration and auxin (IAA, IBA, NAA) being effective at $1.0 \mathrm{mg} / 1$. The combination of $0.5 \mathrm{mg} / 1$ kinetin and $1.0 \mathrm{mg} / 1$ of NAA was found to be ideal for raising whole in vitro plants from the shoot tip explants with healthy shoots, leaves and fully grown

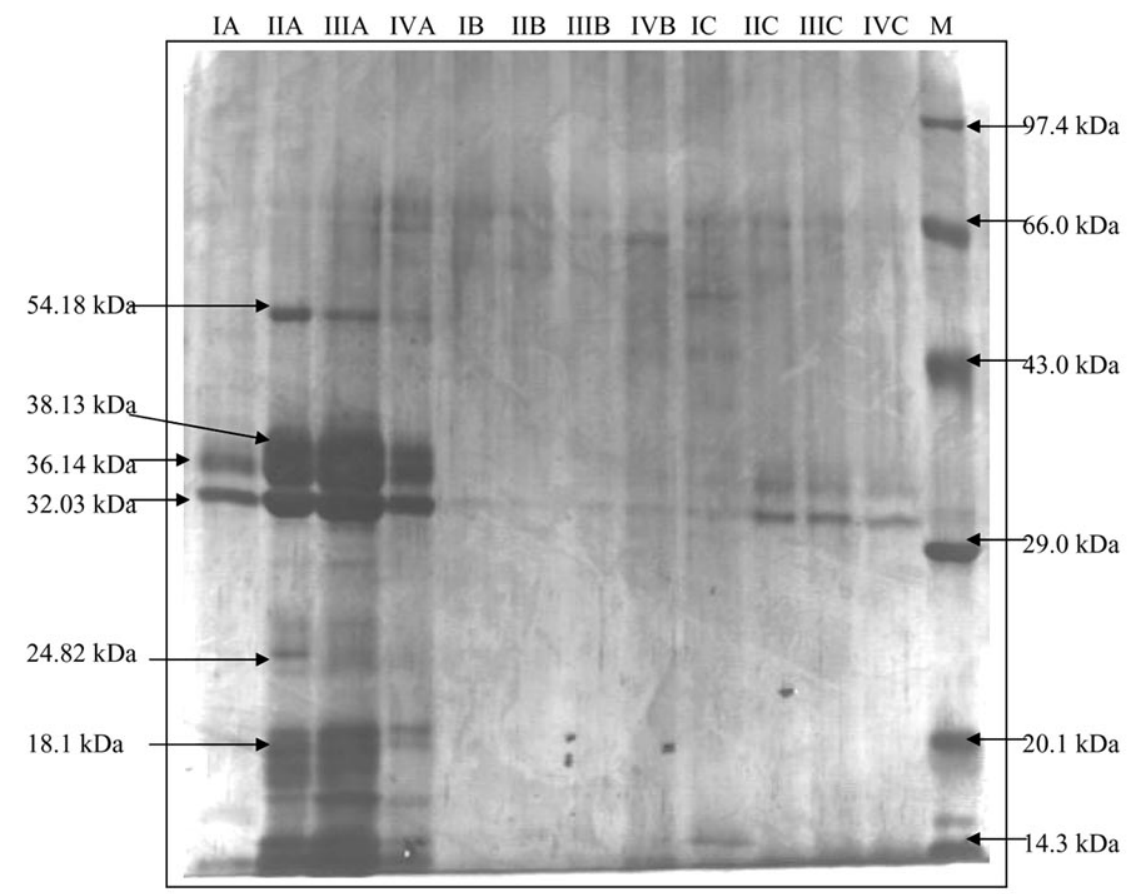

Fig. 6. SDS-PAGE of purified fractions of seed (IA - IVA), in vivo plant leaves (IB - IVB), in vitro raised plant (IC - IVC) and molecular weight marker (M) lane. Ten $\mu \mathrm{g}$ protein of four different elutions was analysed on $10 \%$ SDS-PAGE and silver stained.

roots. A highly efficient and reproducible method of in vitro propagation using meristematic explants was developed for castor. These results are consistent with the earlier reports. Sujatha and Reddy (1998) and Mederos and Schobert (1995) used embryo axes and shoot tips cultured them on MS medium supplemented with adenine, BA, Kn, TDZ and zeatin. We on the other hand used simpler medium as compared to earlier reports using complex media. Thus a highly efficient method was standardized for in vitro propagation of whole Ricinus plants from shoot tips. 
Lectins isolated from seeds, leaves of in vivo and in vitro Ricinus plants using affinity chromatography were purified and characterized. Ricinus galactose binding proteins were purified first by Affinity chromatography column. The four elutions were identified for further analysis. Haemagglutinating activity was present in all the elutions of the three samples.

It was found that the lectins having molecular weight of 29 and $34 \mathrm{kDa}$ were the major constituents of the galactose binding proteins eluted and these correspond to the subunits of ricin and RCA lectins. These proteins were most prominent in seeds and least in in vivo plant leaves. On the contrary a significant amount of these proteins was present in in vitro raised plants. These results are similar with the earlier reports that ricin and RCA are mainly present in seeds (Helmy et al. 2000) and also a new in vitro consistent source(s) of ricin and RCA could be explored. The significant presence of these proteins in in vitro raised plants raises a possibility of obtaining these proteins from lab raised plants for further applications.

$\backslash$

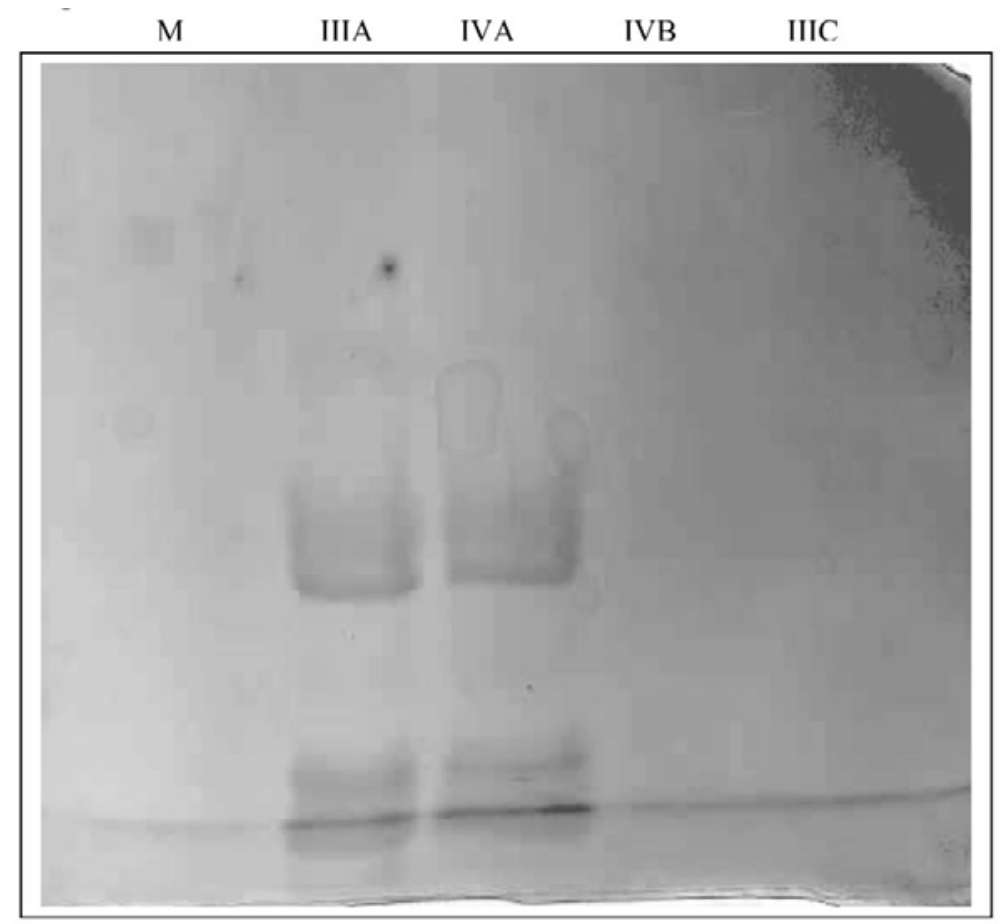

Fig. 7. Schiff's staining of SDS-PAGE gel of purified fractions of seed (IIIA - IVA), in vivo plant leaves (IVB), in vitro raised plant (IIIC) and molecular weight marker (M) lane. Ten $\mu \mathrm{g}$ protein of four different elutions were analysed on 10\% SDS-PAGE. Due to low sensitivity of chromic acid Schiff's staining, the bands were visible only in IIIA and IVA fractions of seed.

Furthermore, there was de novo expression of certain low and high molecular weight lectins present in the purified samples, especially in the seeds. The native 
PAGE was unable to resolve these proteins, which seem to be subunit of high molecular weight proteins. The glycoprotein nature was proved by schiff's staining. Till date most of the work is confined to ricin and RCA lectins that too from seeds (Lord et al. 1994). There are no reports of other glycoproteins from Ricinus. This study demonstrates the presence of and possibility of novel glycoproteins present in the Ricinus seeds and in vitro raised cultures, which can be further characterized, for their beneficial applications like Ricin. In vitro raised plants can be a beneficial source of these lectins other than seeds as in vivo plant leaves do not possess the same property.

The stability of the purified lectins was studied and $\mathrm{pH} 3-7$ was found to be equally favourable for its haemagglutination activity but at higher $\mathrm{pH}$ its activity decreased. Similarly temperature up to $90^{\circ} \mathrm{C}$ was unable to interfere with the haemagglutinating activity but there was gradual decrease in the extent of haemagglutination. All these studies are consistent with the reports of thermo stability and $\mathrm{pH}$ stability of lectins (Curatolo 1982). As reported, the haemagglutinating activity of Hevea brasiliensis lectin (Wittsuwannakul et al. 1998) was heat-stable up to $60^{\circ} \mathrm{C}$ and $P$. filicina up to $50^{\circ} \mathrm{C}$ (Sampaio et al. 1998).

Ribosome-inactivating proteins and agglutinins from callus and suspension cultures of Ricinus communis has been reported earlier (D'Silva et al. 1993). The results of present study are consistent with these reports as there were clear haemagglutinating activity and presence of proteins bands in SDS-PAGE of similar molecular weight in callus as well as in vitro raised plants. They were biologically active, and were found to be comparable with lectins from seeds, in terms of their electrophoretic mobilities. Thus Plant tissue culture techniques can be of immense value for in vitro raising of Ricinus and this can be a source of various useful glycoproteins other than seed.

\section{References}

Bing DH, Weyand JGM and Stavitsky AB (1967) Haemagglutination with aldehyde fixed erythrocytes for assay of antigens and antibodies. Proc. Soc. Exp. Biol. Med. 124: 11661170.

Bradford MM (1976) A rapid and sensitive method for the quantitation of microgram quantities of protein utilizing the principle of protein-dye binding. Anal. Biochem. 72: 248-254.

Curatolo W (1982) Temperature dependence of Ricinus communis agglutinin activity. Biochem. Biophys. Res. Commun. 106(4): 1340-5.

D'Silva I, Vaidyanathan CS and Podder SK (1993) Ribosome-inactivating proteins and agglutinins from callus and suspension cultures of Ricinus communis L. and Abrus precatorius L. Plant Science 161-172. 
Goldstein, IJ and Poretz RD (1986) Isolation, physicochemical characterization and carbohydrate-binding specificity of lectins; in The Lectins: Properties, Functions and Applications in Biology and Medicine, Academic Press Inc., Orlando, USA.

Helmy M. and Pieroni G (2000) RCA60: purircation and characterization of ricin D. isoforms from Ricinus sanguineus. J. Plant Physiol. 156: 477-482.

Lord JM, Roberts LM and Robertus JD (1994) Ricin: structure, mode of action, and some current applications. FASEB J. 8: 201-208

Mederos MS and Schobert C (1995) Micropropagation of Ricinus communis. J. Plant Physiol. 147: 270-272.

Peumans WJ (2000) Higher plants developed structurally different motifs to recognize foreign glycans. Trends Glycosci. Glycotechnol. 12: 83-101.

Pusztai A (1993) Dietary lectins are metabolic signals for the gut and modulate Immune and hormone functions. Eur. J. Clin. Nutr. 47: 691-699.

Sampaio AH, Rogers DSJ and Barwell CJ (1998) A galactose specific lectin from the red marine algae, Ptilota filicina. Phytochemistry 48: 765-769.

Sharon N (1993) Lectin-carbohydrate complexes of plants and animals: An atomic view. Trends Biochem. Sci. 18: 221-226.

Sujatha M and Reddy TP (1998) Differential cytokinin effects on the stimulation of in vitro shoot proliferation from meristematic explants of castor (Ricinus communis L.). Plant Cell Rep. 17: 561-566.

Van Damme EJM, Peumans WJ, Barre A and Rouge P (1998) Plant lectins: A composite of several distinct families of structurally and evolutionary related proteins with diverse biological role. Crit. Rev. Plant Sci. 17: 575-692.

Weiss E (1983) Oilseed Crops, Tropical Agriculture Series. Longman Scientific and Technical, London. 530-564.

Wittsuwannakul R, Wittsuwannakul D and Sakulborirug C (1998) A lectin from the bark of the rubber tree (Hevea brasiliensis). Phytochem. 47: 183 - 187. 